\title{
Prevalence and predictors of dyslipidemia on HAART and HAART naive HIV positive persons in Defense Hospital, Addis Ababa, Ethiopia
}

\author{
Habtamu Wondiferaw Bayenes ${ }^{1}$, Mehidi Kassim Ahmed ${ }^{2}$, Tilahun Yemane Shenkute ${ }^{3}$, \\ Yaregal Asres Ayenew ${ }^{3}$, Lealem Gedefaw Bimerew, \\ ${ }^{1}$ Department of Clinical Laboratory, Defense Hospital, Southwest Ethiopia, Jimma, Ethiopia \\ ${ }^{2}$ Department of Biomedical Sciences, College of Public Health and Medical Sciences, Jimma University, Jimma, Ethiopia \\ ${ }^{3}$ Department of Medical Laboratory Sciences and Pathology, College of Public Health and Medical Sciences, Jimma University, Jimma, \\ Ethiopia
}

\section{Email address:}

wondifrawh@yahoo.com (H. Wondiferaw), mehidika@yahoo.com (M. Kassim) tilaunye@gmail.com (T. Yemane), yaregala3@gmail.com (Y. Asres), lealem.gedefaw@ju.edu.et (L. Gedefaw)

\section{To cite this article:}

Habtamu Wondiferaw Bayenes, Mehidi Kassim Ahmed, Tilahun Yemane Shenkute, Yaregal Asres Ayenew, Lealem Gedefaw Bimerew. Prevalence and Predictors of Dyslipidemia on HAART and HAART Naive HIV Positive Persons in Defense Hospital, Addis Ababa, Ethiopia. American Journal of Health Research. Vol. 2, No. 5, 2014, pp. 303-309. doi: 10.11648/j.ajhr.20140205.23

\begin{abstract}
Background: The introduction of highly active antiretroviral therapy (HAART) has led to a marked reduction in Acquired Immune Deficiency Syndrome (AIDS) related morbidity and mortality. However, HAART has been reported to be associated with a number of side effects in human immunodeficiency virus (HIV) positive persons among which dyslipidemia and lipodystrophy are common metabolic disorders. Objective: To assess the prevalence and predictors of dyslipidemia among HAART and HAART naive HIV positive persons in Defense Hospital, Addis Ababa-Ethiopia. Methods: A facility based comparative cross-sectional study among 228 HIV positive persons was conducted from September to October 2013. Socio-demographic and clinical data were collected using structured questionnaires. Fasting venous blood sample was drawn for laboratory analysis. Lipid profiles were measured using clinical chemistry analyzer (HumStar80, USA). CD4 cell counting was done using BD FACS Count ${ }^{\mathrm{TM}}$ (BD, USA). Anthropometric measurement was done. Data was analyzed using SPSS version 20 for windows. Result: A total of 228, 114 on HAART and 114 HAART naïve HIV positive persons, were enrolled in the study. The overall prevalence of dyslipidemia was $63.6 \%$. Prevalence of dyslipidemia in HAART naive and on HAART HIV positive persons was $61(53.5 \%)$ and $84(73.7 \%)$, respectively. The prevalence of TC $\geq 200 \mathrm{mg} / \mathrm{dl}$ was $50 \%$ and $30 \%$; HLD-c $<40 \mathrm{mg} / \mathrm{dl}$ was $43.8 \%$ and 36\%; LDL-c $\geq 130 \mathrm{mg} / \mathrm{dl}$ was $48.3 \%$ and 28.1\%; and TG $\geq 150 \mathrm{mg} / \mathrm{dl} 59.6 \%$ and $39 \%$ among on HAART and HAART naïve, respectively. Age greater than 40 years old $(\mathrm{AOR}=3.27,95 \%$ C.I: $1.47-7.25)$, blood pressure $\geq 140 / 90(\mathrm{AOR}=16.13,95 \%$ C.I: 5.81 - 44.75), being on HAART $(\mathrm{AOR}=2.73,95 \%$ C.I: $1.35-5.53)$, and body mass index $>25 \mathrm{~kg} / \mathrm{m}^{2}(\mathrm{AOR}=1.92,95 \%$ C.I: $1.20-4.81)$ were identified as determinants of dyslipidemia. Conclusion: The mean value of lipid profile was significantly higher on HAART as compared to HAART naïve HIV positive persons. It is important to have well controlled cohort studies for the evaluation of long-term effects of HAART on lipid profiles.
\end{abstract}

Keywords: Dyslipidemia, HAART, HIV /AIDS, Prevalence, Ethiopia

\section{Introduction}

Acquired Immune Deficiency Syndrome (AIDS) has become the focus of much global concern and that is reaching epidemic proportions in some parts of the world [1]. Different highly active antiretroviral therapy (HAART) regimens currently being in use and in development have been found in different countries for increasing life expectancy and immune status of HIV positive persons [2]. These HAART regimens typically include a combination of at least three drugs, such as different association of protease inhibitors (PI), non-nucleoside reverse transcriptase 
inhibitors (NNRTI) and nucleoside reverse transcriptase inhibitors (NRTI) [3].The introduction of these HAART has led to a marked reduction in AIDS-related morbidity and mortality [4].

In sub-Saharan Africa, the epicenter of HIV pandemic, the widely used first-line antiretroviral regimens, inspired by World Health Organization (WHO), combines two NRTI with a NNRTI [3]. PI are the compulsory components of the second-line treatment subsequent to the failure of the firstline one in which a change from Tenofovir/Lamivudine/Efavirenz (TDF/3TC/EFV) preferred first line combination to Tenofovir/Lamivudine/Lopinavir/r (TDF/3TC/LPV/r) second line combination [5]. This HAART however, has been reported to be associated with a number of side effects in HIV/AIDS persons [6]. Antiretroviral treatments are associated with abnormal changes in the lipid profile in people with HIV infection [79]. This include; elevated level of total cholesterol (TC), lowdensity lipoprotein-cholesterol (LDL-c), triglyceride (TG), and decreased high-density lipoprotein-cholesterol (HDL-c) [10]. Some antiretroviral drugs, such as stavudine (d4T) [11], and PIs [12], increase the blood levels of TC, LDL-c, and TGs with variable effects on levels of HDL-c. Nevirapine (NVP) use is associated with increased in LDL-c [13], whereas increases in TC and TG are observed with use of EFV, particularly with longer duration of therapy.

The exact mechanism for the abnormality of lipid is still not clear and the cause could be multi factorial [14]. The individual contributions of HIV infection, specific antiretroviral agents, host genetics [15] and changes in body composition, all should be considered [16]. A study has shown that HIV replication alone without any influence of antiretroviral drugs enhances production of free fatty acids, lipoproteins and many key proteins associated in lipid synthesis, transport and metabolism [17]. The differential contribution of HAART to lipid abnormalities suggests that hypothetically switching patients from firstline to second-line treatment increase dyslipidemia. These high lipids increase the risk of blood clots, heart disease and heart attack, stroke, and pancreatitis [17] which has an impact on mortality rates [18].

Since the introduction of HAART, morbidity and mortality has decreased greatly in HIV-positive persons. But the use of HAART is now associated with a series of serious side effects such as dyslipidemia and long-term complications that may have an impact on mortality rates. More deaths occurring from liver disease, kidney disease, and cardiovascular complications are being observed in those individuals with factors related to the virus, the host, and ART factors [18-20]. Although dyslipidemia in HIVpositive persons with HAART is common, not all patients with dyslipidemia require lipid lowering therapy. The goal of therapy, as in the HIV negative population, is to reduce an individual's cardiovascular risk. Therefore treatment of HIV-associated dyslipidemia should be an integral part of a general attempt to improve cardiovascular health, with advice on diet and exercise, smoking cessation, management of hypertension and diabetes where present and the use of anti-platelet agents are crucial interventions in managing dyslipidemia [21].

Despite these great upcoming challenges there is limited laboratory monitoring to access all the HAART individuals, even WHO ART guidelines do not include a recommendation that lipid monitoring should be conducted in patients receiving HAART [22]. The prevalence of dyslipidemia on HAART individuals in resource-limited settings also has not been well characterized [23]. This study was aimed at determining whether individuals on HAART have high value of dyslipidemia compared to HAART naive and to assess whether persons on HAART and HAART naive lipid profile assessment is preferential one.

\section{Methodology}

\subsection{Study Area and Period}

A facility based cross-sectional study was conducted in Addis Ababa Defense Referral Hospital from September to October 2013. Addis Ababa is the capital city of Ethiopia. Addis Ababa defense referral hospital has been delivered health services to the Defense forces; civilians in the Ministry of Defense and their dependants as well as public patients referred by other specialty hospitals. The hospital launched a free ART program in 2005. The total numbers of subjects ever enrolled for HIV care were 4,892 of whom 3, 750 were adults. From the total HIV care attendants; 1,627 were on HAART and 1,423 were HAART naïve during the study period.

\subsection{Sample Size and Study Subjects}

The sample size was determined using two population proportion formula by considering the following assumptions: proportion of HIV positive persons on HAART with LDL-c $\geq 130$ (40.8\%) [24] and proportion of HIV positive persons naive for HAART with LDL-c $\geq 130$ $(21 \%)$ [25]. Level of significance $(\alpha / 2)=5 \%$; power $(1-\beta)$ $=90 \% ; \mathrm{r}=($ Ratio of exposed: non exposed $)=1: 1$. By adding $10 \%$ non-response rate and adjusting for the total population the final sample size was 228 (114 on HAART and 114 HAART naïve HIV positive persons).

All HIV positive persons (age $\geq 18$ years) who were available during the study period were included consecutively. On the other hand, HIV positive persons with known diabetes mellitus, renal failure and on anti TB drugs were excluded from the study. In addition, HIV positive persons on HAART who change their regimen in less than a year from the study period and who took HAART for less than a year before the study period were excluded from the study.

\subsection{Data Collection Techniques and Instruments}

Data collectors and supervisor were selected from the hospital; one BSc-nurse for socio-demographic data collection, one phlebotomist and two laboratory technologists for 
laboratory analysis were assigned throughout the data collection period. Structured questionnaire was used for sociodemographic data collection. Past medical history was collected by reviewing patient's records using checklists. Anthropometric measurements, height and weight were done.

\subsection{Blood Specimen Processing and Analysis}

A fasting venous blood sample was drawn for lipid profile and CD4 cell counting in separate test tube using vacutainer blood collection system. Ethylene diamine tetraacetic acid (EDTA) anicoagulated venous blood was processed for CD4 count using BD FACSCount ${ }^{\mathrm{TM}}$ (BD USA).

Venous blood collected in plain tube was allowed to clot, centrifuged for five minutes at 3,000 revolutions per minute and serum was separated for serum lipid measurement. The TC/HDL-c ratio was also calculated. Lipid profile was assessed through enzymatic Methods using Clinical chemistry Analyzer (HumStar80, USA) for all persons and includes total cholesterol (TC), HDL-cholesterol (HDL-c) and triglycerides (TG) but Low-density lipoprotein (LDL) cholesterol was calculated by the Friedewald method (LDL $=$ CHOL $-(\{\mathrm{TG} / 5\}+$ HDL $)$, except in patients with TG levels higher than $400 \mathrm{mg} / \mathrm{dL}$.

In accordance with the US National Cholesterol Education Program, Adult Treatment Panel III (NCEP-ATP III) guidelines, abnormal lipid profile was defined as TC $\geq 200 \mathrm{mg} / \mathrm{dl}$, HDL-c <40mg/dl, LDL-c $\geq 130 \mathrm{mg} / \mathrm{dl}$, TG $\geq 150 \mathrm{mg} / \mathrm{dl}$, TC/HDL-c ratio $\geq 5$ [26]. For the purposes of the study, an elevation of any one of the lipid parameters to a level above these limits was considered as dyslipidemia.

\subsection{Data Quality Assurance}

Questionnaire was translated to local language, Amharic and the Amharic version was used for the interview. Two days training was given to data collectors and supervisor. Weight measurement was done using a digital scale to the nearest $0.1 \mathrm{~kg}$. A fixed base calibrated height scale was used for the height measurement to the nearest $0.1 \mathrm{~cm}$. Measurements were done twice; when necessary any discrepancy was resolved by a third measurement and the mean values were used to compute BMI. All laboratory activities were done strictly following manufacturer's instruction and standard operational procedures (SOPs). All the reagents were checked for their expiry date. Chemistry analyzer was checked for validity using normal (Humatrol $\mathrm{N}$ ) and abnormal (Humatrol P) controls. Low, medium and high controls samples were used for FACS count machine to check its precision and accuracy.

\subsection{Statistical Analysis}

Body mass index (BMI) was calculated as weight in kilogram divided by the square of height in meter using Microsoft Office Excel 2007. Data was coded, entered, and cleaned using Epi-Info version 3.5.4 and then exported to SPSS version 20 for analysis. Descriptive statistics using frequency distribution was performed for socio-demographic and clinical characteristics of study participants. The association between the independent and dependent variables was assessed using binary and multivariable logistic regression analysis. Independent student's T-test was used to compare the mean values of lipid parameters between HAART naïve and on HAART HIV positive persons. The magnitudes of the association between the different independent variables and abnormal lipid profile were expressed in terms of adjusted odds ratio (AOR). All variables with $\mathrm{P}<0.05$ were considered as statistically significant.

\subsection{Ethical Clearance and Consent}

Ethical clearance was obtained from Jimma University Ethical Review Board and a letter of permission to conduct the study was obtained from Defense Hospital clinical director office. Written informed consent was obtained directly from the study participants for adults enrolled in the study after providing information about the purpose and methods of the study. All abnormal results of the patients were reported to the health professionals working in Defense Hospital ART clinic.

\section{Results}

\subsection{General Characteristics of Study Participants}

Table 1. General Characteristics of HIV positive persons in Defense Hospital, Addis Ababa-Ethiopia from September 20 to October 23, 2013.

\begin{tabular}{|c|c|c|c|}
\hline Variable & Categories & $\begin{array}{l}\text { On HAART } \\
\text { No }(\%)\end{array}$ & $\begin{array}{l}\text { HAART } \\
\text { naïve No }(\%)\end{array}$ \\
\hline \multirow[t]{2}{*}{ Sex } & Male & $53(46.49)$ & $50(43.86)$ \\
\hline & Female & $61(53.51)$ & $64(56.14)$ \\
\hline \multirow[t]{3}{*}{ Age in years } & $18-30$ & $24(21.04)$ & $32(28.07)$ \\
\hline & $31-40$ & $67(58.77)$ & $62(54.39)$ \\
\hline & $>40$ & $31(27.20)$ & $20(17.54)$ \\
\hline \multirow[t]{3}{*}{ BMI (Kg/m2) } & $<18.5$ & $5(4.39)$ & $9(7.89)$ \\
\hline & $18.5-25$ & $78(68.42)$ & $87(76.32)$ \\
\hline & $>25$ & $31(27.19)$ & $18(15.79)$ \\
\hline \multirow[t]{2}{*}{ Blood pressure ${ }^{*}$} & $<140 / 90$ & $61(53.51)$ & $68(59.65)$ \\
\hline & $\geq 140 / 90$ & $53(46.46)$ & $46(40.35)$ \\
\hline \multirow[t]{3}{*}{ CD4 cells/mm3 } & $<350$ & $19(16.67)$ & 49 (42.98) \\
\hline & $350-550$ & $52(45.61)$ & $51(44.74)$ \\
\hline & $>550$ & $43(37.72)$ & $14(12.28)$ \\
\hline \multirow[t]{7}{*}{ Type of HAART } & First line & & \\
\hline & ZDV,3TC,EFV & $30(26.32)$ & \\
\hline & ZDV,3TC,NVP & $36(31.58)$ & \\
\hline & TDF,3TC,EFV & $17(14.91)$ & \\
\hline & TDF,3TC,NVP & $26(22.80)$ & \\
\hline & Second line & & \\
\hline & TDF,3TC,LPV/r & $5(4.39)$ & \\
\hline \multirow{5}{*}{$\begin{array}{l}\text { Duration of } \\
\text { HAART (in } \\
\text { months) }\end{array}$} & $12-36$ & $51(44.74)$ & \\
\hline & $36-60$ & $24(21.05)$ & \\
\hline & $60-84$ & $14(12.28)$ & \\
\hline & $84-108$ & $13(11.40)$ & \\
\hline & $>108$ & $12(10.53)$ & \\
\hline
\end{tabular}

N.B: HAART $=$ highly active antiretroviral therapy, No $=$ Number, BMI $=$ Body Mass Index, $\mathrm{Kg} / \mathrm{m} 2$ = Kilo gram per Meter squire, *blood pressure as systolic/diastolic, ZDV = Zidovudine, 3TC = Lamivudine, EFV = Efavirenz, NVP = Neverapine, $\mathrm{TDF}=$ Tenofovir, LPV/r $=$ Lopinavir $/ \mathrm{r}$ 
A total of $228 \mathrm{HIV}$ positive persons were enrolled in this study from whom, majority, $125(54.82 \%)$ were females. Majority of study participants were within the age group of 31-40 years old. The mean age of study participants was 35.31 ( \pm 7.20$)$. The number of patients on ZDV/3TC/NVP,
ZDV/3TC/EFV, TDF/3TC/NVP and TDF/3TC/EFV regimens were $36(31.58 \%), 30(26.32 \%), 26(22.80 \%)$ and $17(14.91 \%)$, respectively (Table1).

\subsection{Dyslipidemia and Characteristics of Lipid Profiles}

Table 2. Serum lipid profiles of study population by HAART status in Defense Hospital, Addis Ababa-Ethiopia from September 20 to October $23,2013$.

\begin{tabular}{llll}
\hline Variable & categories & On HAART No $(\%)$ & HAART naïve No $(\%)$ \\
\hline Total Dyslipidemia & absent & $30(26.32)$ & $53(46.49)$ \\
& present & $84(73.68)$ & $61(53.51)$ \\
TC & $<200 \mathrm{mg} / \mathrm{dl}$ & $57(50.00)$ & $80(70.18)$ \\
& $\geq 200 \mathrm{mg} / \mathrm{dl}$ & $57(50.00)$ & $34(29.82)$ \\
HDL-c & $<40 \mathrm{mg} / \mathrm{dl}$ & $50(43.86)$ & $41(36.96)$ \\
& $\geq 40 \mathrm{mg} / \mathrm{dl}$ & $64(56.14)$ & $73(64.04)$ \\
LDL-c & $<130 \mathrm{mg} / \mathrm{dl}$ & $59(51.75)$ & $82(71.93)$ \\
& $\geq 130 \mathrm{mg} / \mathrm{dl}$ & $55(48.25)$ & $32(28.07)$ \\
TG & $<150 \mathrm{mg} / \mathrm{dl}$ & $46(40.35)$ & $70(61.40)$ \\
TC/HDL-c ratio: & $\geq 150 \mathrm{mg} / \mathrm{dl}$ & $68(59.65)$ & $44(3860)$ \\
& $<5$ & $57(50.00)$ & $77(67.54)$ \\
\hline
\end{tabular}

N.B: NO = Number, HAART $=$ highly active antiretroviral therapy, TC $=$ total cholesterol, HDL-c $=$ High-Density Lipoprotein-cholesterol, LDL-c $=$ LowDensity Lipoprotein-cholesterol, TG = triglyceride, TC/HDL-c ratio = total cholesterol/High-Density Lipoprotein-cholesterol ratio

Table 3. Comparison of the mean of variables by HAART status at Defense Hospital, Addis Ababa-Ethiopia from September 20 to October 23, 2013

\begin{tabular}{|c|c|c|c|c|}
\hline Variable & Group & $\operatorname{Mean}($ SD) & $\mathrm{t}(95 \% \mathrm{CI})$ & P-value \\
\hline \multirow[t]{2}{*}{ Age in years } & HAART naive & $34.42(6.49)$ & & \\
\hline & On HAART & $36.3(7.81)$ & $1.98(0.01,3.74)$ & 0.318 \\
\hline \multirow[t]{2}{*}{$\mathrm{TC}$} & HAART naive & $186.67(24.09)$ & & \\
\hline & On HAART & $202.39(23.98)$ & $4.90(9.41,21.88)$ & $<0.001$ \\
\hline \multirow[t]{2}{*}{ HDL-c } & HAART naive & $43.85(7.91)$ & & \\
\hline & On HAART & $40.52(6.09)$ & $-3.49(-5.18,-1.53)$ & $<0.001$ \\
\hline \multirow[t]{2}{*}{ LDL-c } & HAART naive & 111.35 (24.79) & & \\
\hline & On HAART & $126.03(22.86)$ & $4.61(8.84,19.81)$ & $<0.001$ \\
\hline \multirow[t]{2}{*}{ TG } & HAART naive & $155.24(23.34)$ & & \\
\hline & On HAART & $175.96(36.81)$ & $5.11(11.90,28.16)$ & $<0.001$ \\
\hline \multirow[t]{2}{*}{ CD4 Cells/mm3 } & HAART naive & $339.18(75.88)$ & & \\
\hline & On HAART & $500.23(157.25)$ & $9.89(128.55,193.13)$ & $<0.001$ \\
\hline \multirow[t]{2}{*}{ BMI in $\mathrm{kg} / \mathrm{m} 2$} & HAART naive & $22.11(2.63)$ & & \\
\hline & On HAART & $23.33(2.72)$ & $3.40(0.54,1.92)$ & 0.862 \\
\hline \multirow[t]{2}{*}{ TC/HDL-c ratio } & TCHAART naive & $4.44(1.17)$ & & \\
\hline & On HAART & $5.17(1.26)$ & $4.5(0.44,1.18)$ & 0.534 \\
\hline
\end{tabular}

N.B: SD = Standard Deviation, HAART $=$ highly active antiretroviral therapy, CI $=$ Confidence Interval, TC $=$ total cholesterol, HDL-c $=$ High-Density Lipoprotein-cholesterol, LDL-c = Low-Density Lipoprotein-cholesterol, TG = triglyceride, TC/HDL-c ratio= total cholesterol/High-Density Lipoproteincholesterol ratio, $\mathrm{BMI}=$ Body Mass Index

Among all study participants involved in the study, 84 $(73.68 \%)$ on HAART and $61(53.51 \%)$ HAART naive persons had at least one lipid abnormality. The prevalence of dyslipidemia on HAART for TC, LDL-c \& TG was greater than HAART naïve which was significantly different. The Mean value of TC, LDL-c, TG were higher in persons on HAART than in HAART-naïve whereas the mean value of HDL-c was higher among HAART-naïve than on HAART HIV positive persons (Table 2, 3).

\subsection{Dyslipidemia and Risk Factors}

Multivariable logistic regression analysis was done for all explanatory variables having $\mathrm{p}<0.25$ in binary logistic regression analysis. Age, CD4 cell count, BMI, blood pressure, and HAART status were analyzed through this method. After controlling potential confounding factors in multiple logistic regression analysis; age greater than 40 years old $(\mathrm{AOR}=3.27$, 95\% C.I: 1.47 - 7.25), blood pressure $\geq 140 / 90(A O R=16.13$, 95\% C.I: 5.81 - 44.75), 
being on HAART $($ AOR $=2.73,95 \%$ C.I: $1.35-5.53)$, and body mass index $>25 \mathrm{~kg} / \mathrm{m} 2(\mathrm{AOR}=1.92,95 \%$ C.I:
1.20 - 4.81) were identified as determinants of dyslipidemia (Table 5).

Table 4. Associations of variables with dyslipidemia among persons on HAART and HAART naive in Defense Hospital, Addis Ababa-Ethiopia from September 20 to October 23, 2013

\begin{tabular}{|c|c|c|c|c|c|}
\hline \multirow{2}{*}{ Explanatory Variable } & & \multicolumn{4}{|c|}{ Outcome variables in mg/dl (95 \% CI) } \\
\hline & & $\mathrm{TC} \geq 200$ & HDL-c $<40$ & LDL-c $\geq 130$ & TG $\geq 150$ \\
\hline \multirow[t]{2}{*}{ Male } & COR & $1.01(0.58-1.72)$ & $1.6(0.57-1.63)$ & $1.10(0.65-1.92)$ & $1.23(0.71-2.01)$ \\
\hline & $\mathrm{P}$-value & 0.990 & 0.880 & 0.720 & 0.510 \\
\hline \multirow[t]{2}{*}{ Age $>40$ years old } & COR & $4.88(2.05-11.61)$ & $4.32(1.12-16.54)$ & $4.05(1.77-9.27)$ & $9.20(2.39-35.49)$ \\
\hline & $\mathrm{P}$-value & 0.001 & 0.030 & 0.001 & $<0.001$ \\
\hline \multirow[t]{2}{*}{ CD4 $<350$ cells $/ \mathrm{mm} 3$} & COR & $3.31(1.50-7.28)$ & $2.06(0.96-4.44)$ & $4.00(1.80-8.87)$ & $3.39(1.52-7.58)$ \\
\hline & $\mathrm{P}$ & 0.003 & 0.062 & 0.001 & 0.003 \\
\hline \multirow[t]{2}{*}{$\mathrm{BMI}>25 \mathrm{~kg} / \mathrm{m} 2$} & COR & $2.01(1.34-6.15)$ & $5.22(2.63-10.72)$ & $3.20(1.71-7.55)$ & $10.83(1.38-84.37)$ \\
\hline & $\mathrm{P}$-value & $<0.011$ & $<0.001$ & $<0.001$ & $<0.001$ \\
\hline \multirow[t]{2}{*}{ On HAART } & COR & $2.34(1.36-4.02)$ & $1.44(0.85-2.41)$ & $2.46(1.42-4.23)$ & $2.53(1.49-4.31)$ \\
\hline & $\mathrm{P}$-value & 0.002 & 0.180 & 0.001 & $<0.001$ \\
\hline \multirow{2}{*}{ Blood pressure $\geq 140 / 90^{*}$} & COR & $25.32(12.43-51.59)$ & $8.01(4.40-14.57)$ & $16.87(8.62-33.01)$ & $9.44(5.12-17.41)$ \\
\hline & P-value & $<0.001$ & $<0.001$ & $<0.001$ & $<0.001$ \\
\hline
\end{tabular}

N.B: COR = Crude Odes Ratio, CI = Confidence Interval, TC = total cholesterol, HDL-c = High-Density Lipoprotein-cholesterol, LDL-c $=$ Low-Density Lipoprotein-cholesterol, TG = triglyceride, BMI = Body Mass Index, HAART = highly active antiretroviral therapy, *blood pressure as systolic/diastolic

Table 5. Determinant factors of Dyslipidemia and lipid profile level among HIV positive persons, adjusted for the potential confounding factors of study participants in Defense Hospital, Addis Ababa-Ethiopia from September to October, 2013

\begin{tabular}{|c|c|c|c|c|c|c|}
\hline \multirow{2}{*}{ Explanatory Variable } & & \multirow{2}{*}{ Dyslipidemia } & \multicolumn{4}{|c|}{ lipid profile level in mg/dl (95 \% CI) } \\
\hline & & & $\mathrm{TC} \geq 200$ & HDL-c $<40$ & LDL-c $\geq 130$ & $\mathbf{T G} \geq \mathbf{1 5 0}$ \\
\hline \multirow[t]{2}{*}{ Age $>40$ years old } & AOR & $3.27(1.47-7.25)$ & & & & $2.44(1.06-5.64)$ \\
\hline & P-value & 0.004 & & & & 0.037 \\
\hline \multirow[t]{2}{*}{$\mathrm{BMI}>25 \mathrm{~kg} / \mathrm{m} 2$} & AOR & $1.92(1.20-4.81)$ & $2.31(1.04-7.66)$ & & $3.20(1.71-7.55)$ & $\begin{array}{l}10.83(1.38- \\
84.37)\end{array}$ \\
\hline & P-value & 0.044 & 0.025 & & $<0.001$ & $<0.001$ \\
\hline \multirow[t]{2}{*}{ On HAART } & AOR & $2.73(1.35-5.53)$ & $3.15(1.49-6.68)$ & & $3.02(1.42-4.23)$ & $2.87(1.51-5.45)$ \\
\hline & P-value & 0.005 & 0.003 & & 0.002 & 0.001 \\
\hline \multirow[t]{2}{*}{ Blood pressure $\geq 140 / 90$} & AOR & $16.13(5.81-44.75)$ & $\begin{array}{l}28.59(13.39- \\
61.04)\end{array}$ & $\begin{array}{l}5.24(2.69- \\
10.22)\end{array}$ & $\begin{array}{l}18.44(9.10- \\
37.41)\end{array}$ & $7.08(3.45-14.53)$ \\
\hline & $\mathrm{P}$-value & $<0.001$ & $<0.001$ & $<0.001$ & $<0.001$ & $<0.001$ \\
\hline
\end{tabular}

N.B: AOR = Adjusted Odes Ratio, CI = Confidence Interval, TC = total cholesterol, HDL-c $=$ High-Density Lipoprotein-cholesterol, LDL-c $=$ LowDensity Lipoprotein-cholesterol, TG = triglyceride, BMI = Body Mass Index, HAART = highly active antiretroviral therapy, *blood pressure as systolic/diastolic.

\section{Discussion}

The general prevalence of dyslipidemia in this study was $145(63.60 \%)$, of these $84(73.68 \%)$ were on HAART and $61(53.51 \%)$ were HAART naïve HIV positive persons. The mean value of TC, LDL-c, TG were higher in persons on HAART than HAART-naïve HIV positive persons, whereas, the mean value of HDL-c was higher among HAART-naïve than on HAART HIV positive persons. According to this study, the mean value of CD4 cell count on HAART group was significantly different from the HAART naïve HIV positive persons. But, CD4 cell count was not significantly associated with dyslipidemia and lipid profile level. This might be due to the effects of HAART in improving the immunological status of the HIV positive individuals [27].

The mean value of each lipid profile in our study was significantly higher among on HAART HIV positive persons than HAART naïve persons which was similar with a study conducted in Sao Paulo, Brazil [28]. We found that the proportions of raised TC, LDL-c, TG and TC/HDL-c ratio were significantly higher among on HAART HIV positive persons when compared to HAART naive participants which indicates the atherogenic effect of treatment for the development of cardiovascular diseases $[10,18]$. The association between HAART and adverse lipid profile has been largely described for regimens when hypothetically switching patients from first-line to secondline treatment [17].

The proportion of patients with $\mathrm{TC} \geq 200 \mathrm{mg} / \mathrm{dl}$ among participants on HAART $(50 \%)$ was higher than the findings reported from; Cameron (37.7\%), Hawassa-Ethiopia $(43.4 \%)$ \& Jimma-Ethiopia $(6.4 \%)$ [24, 29, 30]. This variation might be due to difference in sampling technique, the cut of value used. In Jimma the cut of value was TC $\geq$ $240 \mathrm{mg} / \mathrm{dl}$. A prospective study conducted in India for the effect of NNRTIs forwarded the proportion of patients with TC $\geq 200 \mathrm{mg} / \mathrm{dl}$ had increased from $1-26 \%$ after 12 months of treatment [31].

The prevalence of HDL-c $<40 \mathrm{mg} / \mathrm{dl}$ among on HAART 
HIV positive persons was $43.8 \%$. This is comparable with the prevalence reported from Hawasa-Ethiopia which is $43.4 \%$ [29]. However, the prevalence of HDL-c < 40mg/dl among on HAART HIV positive persons is higher than the prevalence reported from Jimma-Ethiopia (32.6\%) [30]. The prevalence of LDL-c $\geq 150 \mathrm{mg} / \mathrm{dl}$ in our HAART group was $48.3 \%$. It is comparable with the prevalence reported from Cameron which was $46.4 \%$ [24]. The prevalence of raised TG on HAART group was $59.6 \%$, which is comparable with the report from Hawasa-Ethiopia (55.8\%) [29]. But our finding was higher than studies done in; India, Cameron, Jimma-Ethiopia [24, 30, 31] reported 32\%, 39\%, $18.2 \%$, respectively. However, there are suggestions that the magnitude of lipid profile derangements induced by HAART showed variation with duration of treatment, across populations and setting.

\section{Conclusion}

In conclusion, the raised TC, LDL-c and TG values were significantly and positively associated with the use of HAART treatment. The mean value of all lipid profile was significantly higher among on HAART HIV positive persons as compared to HAART naïve HIV positive persons. Increased age and blood pressure, being on HAART, and increased in body mass index were the determinant factors of dyslipidemia among HIV positive persons. Therefore, further longitudinal studies with long term follow-up are needed to explore more on the causes of dyslipidemia and the pattern of lipid profile changes with HAART initiation in HIV positive persons in resource limited settings.

\section{Acknowledgment}

We would like to thank our data collectors for their invaluable effort. Our deep gratitude also goes to our study subjects who were volunteer and took their time to give us all the relevant information for the study.

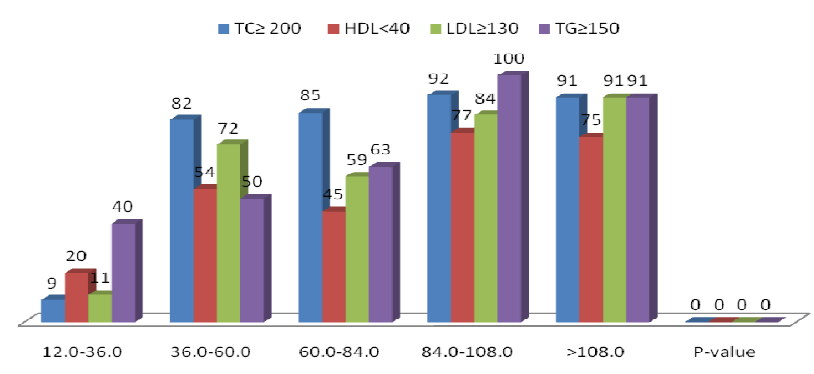

Figure 1. Dyslipidemia among persons on HAART by duration of therapy in Defense Hospital, Addis Ababa-Ethiopia.

N.B:

$\mathrm{TC}=$ total cholesterol, HDL-c $=$ High-Density Lipoprotein-cholesterol, LDL-c = Low-Density Lipoprotein-cholesterol, TG = triglyceride, The number of study participants on HAART were 53, 22, 14, 13 and 12 for $12-36,36-60,60-84,84-108$ and $>108$ periods of therapy in months respectively with $\mathrm{Y}$-axis dyslipidemia in percent and $\mathrm{X}$-axis duration of therapy in months.

\section{References}

[1] A.S. Fauci, E. Brawnwald, D.L. Kasper, S.L. Hauser, D.L. Longo, J.L. Jameson, et al., "Harrison's Principles of Internal Medicine," 17th ed., McGraw-Hill Medical Publishing Division: New York, 2008.

[2] D. Rouleau, C. Fortin, B. Trotier, R. Lalonde, N. Lapointe, P. Cote, et al., "Antiretroviral therapy for adults infected with HIV: Guidelines for health care profesionals from Quebec HIV care commettee," Can J Infect Dis Med Microbiol, Vol. 22(2), pp.52-60, 2011.

[3] T. Gsponer, M. Petersen, M. Egger, S. Phiri, M.H. Maathuis, A. Boulle, et al., "The causal effect of switching to secondline ART in programmes without access to routine viral load monitoring," AIDS, Vol. 26(1), pp57-65, 2012.

[4] W.T. Enanoria, C. Ng, S.R. Saha, Jr. JM. Colford, "Treatment outcomes after highly active antiretroviral therapy: a meta-analysis of randomised controlled trials," Lancet Infect Dis, Vol.4 (7), pp.414-25, 2004.

[5] WHO, "Antiretroviral therapy for HIV infection in adults and adolescents: recommendations for a public health approach," Geneva, World Health Organization, 2006.

[6] C. Lewden, T. May, E. Rosenthal, C. Burty, F. Bonnet, D. Costagliola, et al., "Changes in causes of death among adults infected by HIV between 2000 and 2005: The "Mortalité 2000 and 2005" surveys (ANRS EN19 and Mortavic)," J Acquir Immune Defic Syndr, 48(5):590-8, 2008.

[7] C. Grunfeld, "Dyslipidemia and its treatment in HIV infection,” Top HIV.Med, Vol. 18, pp. 112-18, 2010.

[8] JG.Troll, "Approach to dyslipidemia, lipodystrophy, and cardiovascular risk in patients with HIV infection," Curr Atheroscler Rep, Vol.13 (1), pp. 51-6, 2011.

[9] Australian Institute of Health and Welfare 2010, "Australia's health 2010," Australia's health series no. 12. Cat. No. AUS 122.Canberra: AIHW.

[10] W.M. El-Sadr, C.M. Mullin, A. Carr, C. Gibert, C. Rappoport, F. Visnegarwala, et al., "Effects of HIV disease on lipid, glucose and insulin levels: results from a large antiretroviral-naive cohort," HIV Med. Vol. 6(2), pp.114-21, 2005.

[11] J.E. Gallant, S. Staszewski, A.L. Pozniak, E. DeJesus, JMAH Suleiman, MD. Miller, et al., "Efficacy and safety of tenofovir DF vs stavudine in combination therapy in antiretroviral-naive patients: a 3-year randomized trial," JAMA, Vol.292 (2), pp.191-201, 2004.

[12] K. Anastos, D. Lu, Q. Shi, PC. Tien, RC. Kaplan, NA. Hessol, et al., "Association of serum lipid levels with HIV serostatus, specific antiretroviral agents, and treatment regimens," J Acquir Immune Defic Syndr, Vol.45 (1), pp. 34-42, 2007.

[13] V. M. Vander, J.J. Kastelein, R.L. Murphy, F. Van Leth, C. Katlama, A. Horban, et al., "Nevirapine-containing antiretroviral therapy in HIV-1 infected patients results in an anti atherogenic lipid profile," AIDS, Vol. 15(18), pp. 24072414,2001 
[14] A. Carr, K. Samaras, S. Burton, M. Law, J. Freund, D.J. Chisholm, et al., "A syndrome of peripheral lipodystrophy, hyperlipidaemia and insulin resistance in patients receiving HIV protease inhibitors," AIDS, Vol. 12(7), pp.F51-8, 1998.

[15] S.P. Jones, O. Janneh, D.J. Back, M. Pirmohamed, “Altered adipokine response in murine 3T3-F442A adipocytes treated with protease inhibitors and nucleoside reverse transcriptase inhibitors," Antivir Ther (Lond), Vol. 10(2), pp. 207-13, 2005.

[16] J. Young, R. Weber, M. Rickenbach, H. Furrer, E. Bernasconi, B. Hirschel, et al., "Lipid profiles for antiretroviral-naive patients starting PI- and NNRTI-based therapy in the Swiss HIV cohort study," Antivir Ther (Lond), Vol. 10(5), pp.585-91, 2005.

[17] S. Rasheed, J.S. Yan, A. Lau, A.S. Chan, "HIV replication enhances production of free fatty acids, low density lipoproteins and many key proteins involved in lipid metabolism: a proteomics study," PLoS ONE. Vol. 3(8):e3003, 2008.

[18] A. Mastroianni, "Emergence of Sjogren's syndrome in AIDS patients during highly active antiretroviral therapy," AIDS. Vol.18 (9), pp. 1349-52, 2004.

[19] M. Shahmanesh, H. Jaleel, Y. De Silva, "Protease inhibitor related type III hyper lipoproteinaemia is common and not associated with apolipoprotein-E E2/E2 phenotype," Sex Transm Infect, Vol. 77, pp. 283-6, 2001.

[20] M.S. Rhee, J.A. Hellinger, S. Sheble-Hall, C.J. Cohen, D.J. Greenblatt, "Relationship between plasma protease inhibitor concentrations and lipid elevations in HIV patients on a double-boosted protease inhibitor regimen (saquinavir/lopinavir/ritonavir)," J Clin Pharmacol, Vol. 50(4), pp.392-400, 2010.

[21] E.R. Feeney, P.WG. Mallon, "HIV and HAART-Associated Dyslipidemia," Open Cardiovasc Med J, Vol.5, pp.49-63, 2011.

[22] Ministry of health and social services directorate of special programmes, "National Guidelines for Antiretroviral Therapy," 3rd ed., 2010. WHO, "HIV Care \& PMTCT in Resource-Limited Settings: Monthly Intelligence Report," Vol.6 (1), 2010.
[23] E.W. Pefura Yone, A.F. Betyoumin, A.P. Kengne, F.J. Kaze Folefack, J.Ngogang, "First-line antiretroviral therapy and dyslipidemia in people living with HIV-1 in Cameroon: a cross-sectional study," AIDS Res Ther. Vol. 8, pp. 33, 2011.

[24] EM. Manuthu, M.D. Joshi, G.N. Lule, E. Karari, "Prevalence of dyslipidemia and dysglycaemia in HIV infected patients," East Afr Med J, Vol. 85(1), pp.10-7, 2008.

[25] National Cholesterol Education Program (NCEP), "Third Report of the National Cholesterol Education Program (NCEP) Expert Panel on Detection, Evaluation, and Treatment of High Blood Cholesterol in Adults (Adult Treatment Panel III) final report," Circulation, Vol.106(25), pp.3143-421, 2002.

[26] F.F. Akinola, A.A. Akinjinmi, O.O. Oguntibeju, "Effect of Combined Antiretroviral Therapy on Selected Trace Elements and CD4+T-cell Count in HIV Positive Persons in an African Setting," J AIDS Clinic Res, Vol.3(1850. doi: 10.4172/2155-6113.1000185), 2012.

[27] EFR. Silva, K.C. Bassichetto, D.S. Lewi, "Lipid profile, cardiovascular risk and AIDS,"Arq Bras Cardiol, Vol. 93(2), pp.107-111, 2009.

[28] A. Tadewos, Z. Addis, H. Ambachew, S.Banerjee, "Prevalence of dyslipidemia among HIV-infected patients using first-line highly active antiretroviral therapy in Southern Ethiopia: a cross-sectional comparative group study," AIDS Res Ther, Vol. 9(1), pp. 31, 2012.

[29] T. Berhane, A. Yami, F. Alemseged, T. Yemane, L. Hamza, M. Kassim, et al., "Prevalence of lipodystrophy and metabolic syndrome among HIV positive individuals on Highly Active Anti-Retroviral treatment in Jimma, South West Ethiopia," Pan Afr Med J, Vol.13, pp.43, 2012.

[30] C. Padmapriyadarsini, S. Ramesh Kumar, N. Terrin, G. Narendran, P.A. Menon, G. Ramachandran, et al., "Dyslipidemia among HIV-infected Patients with tuberculosis taking once-daily nonnucleoside reversetranscriptase inhibitor-based antiretroviral therapy in India," Clin Infect Dis, Vol.52(4), pp.540-6, 2011. 